\title{
Influencia del humanismo en la arquitectura de los Jesuitas: Iglesia de San Luis de los Franceses de Sevilla
}

\author{
Manuel V. Castilla \\ Universidad de Sevilla
}

RESUMEN:

El análisis de la relación directa de los términos "estilo jesuítico" y "noster modus" con las teorías arquitectónicas del Humanismo como aglutinante de la llamada arquitectura de los jesuitas es una parte fundamental del trabajo. A partir de esta hipótesis, hemos utilizado la tipología de San Luis de los Franceses, (Sevilla), como ejemplo característico de la funcionalidad, ornato y lenguaje decorativo de la arquitectura jesuítica. Considerada como de las arquitecturas más notables de la Compañía de Jesús, es destacable su planta centrada en forma de cruz griega inscrita en un rectángulo, poco conocida en Sevilla. El diseño de la arquitectura basado en sus propias reglas constructivas ha sido un hito de la historia de arquitectura occidental. Esta forma de proceder respetaba el pensamiento humanista en el que la casa de Dios debía simbolizar la perfección, armonía, belleza e integridad del Creador.

\section{PALABRAS CLAVE:}

Humanismo; Arquitectura jesuítica; Barroco; Perspectiva Lineal; Noster modus.

\section{ABSTRACT}

The analysis of the direct relationship of the terms "jesuit style" and "noster modus" (our way of proceeding), with the architectural theories of Humanism as a binder of what it is called Jesuit Architecture, it is also a fundamental part of this work. From this hypothesis, we used the typology of St. Louis of the French in Seville, as an example of ornamental and decorative language of Jesuit architecture. This church is considered one of the most remarkable architectures of the Society of Jesus. It is noteworthy its centered floor plan in the shape of a Greek cross inscribed in a rectangle. This is plan is little known in Sevillian Architecture. The design of the architecture based on Jesuitical construction rules has been a milestone in Western architectural history. This way of proceeding respected humanist thinking, in which the household of God was supposed to symbolize perfection, harmony, beauty and integrity of Creator.

\section{KEYWORDS:}

Humanism; Jesuit Architecture; Baroque; Linear Perspective; Noster modus. 


\section{INTRODUCCIÓN}

Es conocido, que el Humanismo intentó la conciliación de la filosofía y creencias clásicas, con el pensamiento cristiano. Con estas premisas es fácil entender que en la Europa del siglo $\mathrm{XV}$ se desarrollara una literatura, concretamente obras de mitología clásica, que repercutía extraordinariamente en las artes y que de alguna manera era perceptible en la arquitectura. Estos valores clásicos que de alguna forma son patentes en la modernidad, están presentes en la arquitectura sacra del Humanismo unificando lo "clásico" con lo "cristiano" y así continuará durante el Barroco. En este sentido, son de suma importancia las observaciones y estudios de R. Wittkower, (1901-1971) porque abrieron nuevas líneas de investigación para hacer una verdadera historia de la Arquitectura en un continuo diálogo con la Historia del Arte. Wittkower defiende una arquitectura renacentista hundida en las raíces del pensamiento cristiano del Humanismo y el movimiento neoplatónico con el noble objetivo de hermanar la filosofía clásica con la revelación. La verdadera belleza residía en Dios y el arte tenía como objetivo principal la representación de Dios.

El concepto neoplatónico del hombre como un microcosmos proporcionado y armónico en el orden natural creado por Dios tuvo una gran repercusión en el Renacimiento. No es casual que cuando se produce un alejamiento de la ideología cristiana y a su vez un acercamiento hacia el protagonismo del hombre surja el $\mathrm{Hu}-$ manismo y se consideren otras intenciones en la representación del arte como es el caso de la arquitectura.

Por ello, el contexto en el que los arquitectos tuvieron que ejercer sus cualidades artísticas en el diseño y construcción de arquitecturas sacras se caracterizó por una compleja transición hacia la Edad Moderna y en la arquitectura concretamente, hacia el Renacimiento. Por otro lado, la intensificación de cambios profundos en los espacios dedicados al culto decididos en el concilio de Trento, tanto desde el punto de vista de sus formas de representación artística como en su adecuación a las necesidades propias de las tareas evangelizadoras, tuvieron que ser aceptados para componer alternativas arquitectónicas capaces de satisfacer las exigencias conciliares.

El manual que recogía la interpretación de la arquitectura para la religión católica fue orga- nizado por el cardenal Carlo Borromeo, (15381584) con el título Fabricae et Supellectilis Ecclesiasticae ${ }^{1}$. En 1577 Borromeo decidió que la planta de la iglesia tenía que ser de cruz latina contrariamente a la pretendida planta central de los arquitectos del Renacimiento y el mismo Vignola ${ }^{2}$, arquitecto de la Iglesia Madre Il Gesú de Roma, tuvo que aceptar las instrucciones del cardenal Farnesio sobre la eliminación de naves laterales, cubrición de bóveda y orientación de fachada. En este sentido, Wittkower, se manifiesta y escribe:

\section{“[...], los constructores de iglesias en Ita-} lia fueron abandonando progresivamente la tradicional planta de cruz latina formada por una larga nave, un transcepto y un coro. En su lugar, abogaron por las iglesias de planta central, iglesias que han sido consideradas siempre como el máximo exponente de la arquitectura renacentista"s.

En el caso particular de los jesuitas, que será al que nos referiremos por su extraordinaria importancia, es el momento en el que la Compañía se plantea la composición de una alternativa arquitectónica capaz de atender sus propias necesidades y principios operativos. Así, en la Primera Congregación General de la Compañía de Jesús constituida en 1558, se estableció un catálogo de reglas y preceptos generales dirigidos a las nuevas construcciones entre los que podemos destacar los referentes a la utilidad, sanidad, robustez y sencillez ${ }^{4}$. Pero esta idea inicial fundacional de austeridad y simplicidad, concordante con la negación de la importancia del ornamento en la arquitectura humanista fue gradualmente flexibilizada, posibilitando el exuberante barroquismo de algunas iglesias como Il Gesú de Roma o San Luis de los Franceses de Sevilla, entre otras. El proyecto arquitectónico de esta iglesia lo desarro-

\footnotetext{
BORROME0, Carlo. "Instrucciones Fabricae et Supellectilis Ecclesiasticae, 1577”, en Arquitectura Barroca, Aguilar, Madrid, 1989.

2 FAGIOLO, Marcello. Vignola: L'architettura dei principi. Gangemi Editori. Roma. 2007.

3 WITTOKOWER, Rudolf. Los Fundamentos de la Arquitectura en la Edad del Humanismo. Trad. Adolfo Gómez Cedillo. Alianza Editorial. Madrid.1995. pp.15-16. 4 VALERY-RADOT, Jean. Le recueil de plans d'edifices de la Compagnie de Jesus a la Biblioteque Nationale de Paris. Institutum Historicum. S.I., Roma. 1960.
} 
lló el arquitecto externo Leonardo de Figueroa ${ }^{5}$, (1654-1731) impregnándolo de influencias borrominescas y a su vez, de una acentuada personalidad sevillana, fig. 1 .

Una vez definida la planificación general la Reglas Provinciales exigían la aprobación por el Padre General de la Compañía de cualquier proyecto constructivo. Este alto cargo tenía la competencia sobre el llamado "noster modus", desde nuestro punto de vista, no equivalente a "estilo jesuítico". Asimismo, una circular del año 1566 advertía a los provinciales de la obligación de la aprobación por Roma de cualquier edificio relevante, con la finalidad de evitar construcciones que pudieran durar poco o ejecutar construcciones sin proyecto. Con objeto de permitir una planificación organizada y centralizada, una vez expandida la Compañía por todo el mundo, esta creó estructuras de gestión y control de los proyectos procedentes de distintos territorios. Ya en 1565, la Segunda Congregación General creó la figura del consiliarius aedificorum o asesor en temas arquitectónicos ${ }^{6}$ precisando que las provincias deberían enviar a Roma sus planos y proyectos para ser analizados por dicho consiliarius. Esta decisión pudo ser la primera causa que permitiera la derivación de la homogenización arquitectónica hacia la conciencia de un estilo propio.

El primer consiliarius fue el hermano coadjutor Giovanni Tristano ${ }^{7}$, religioso que adquirió una buena formación arquitectónica y que permaneció en el cargo hasta 1575. Fue considerado el creador e intérprete del mal llamado "noster modus" en la arquitectura de los jesuitas, y participó en innumerables obras, siendo su común denominador las iglesias de una sola nave en cruz latina basada en la tradición basilical por la amplitud y unidad de espacio, donde todos los puntos de fuga convergían en el Altar Mayor. Los criterios de Tristano fueron básicos para la adopción de tipologías arquitectónicas "a la moderna" como se denominaban las edificaciones relacionadas con el Renacimiento, naciendo así una típica "arquitectura de los jesuitas", (mejor que "estilo jesuítico"). A su muerte, Tristano fue sustituido por el hermano coadjutor arquitecto y pintor Giuseppe Valeriano ${ }^{8}$, buen conocedor de España y que, según algunos investigadores, participó en la fase final
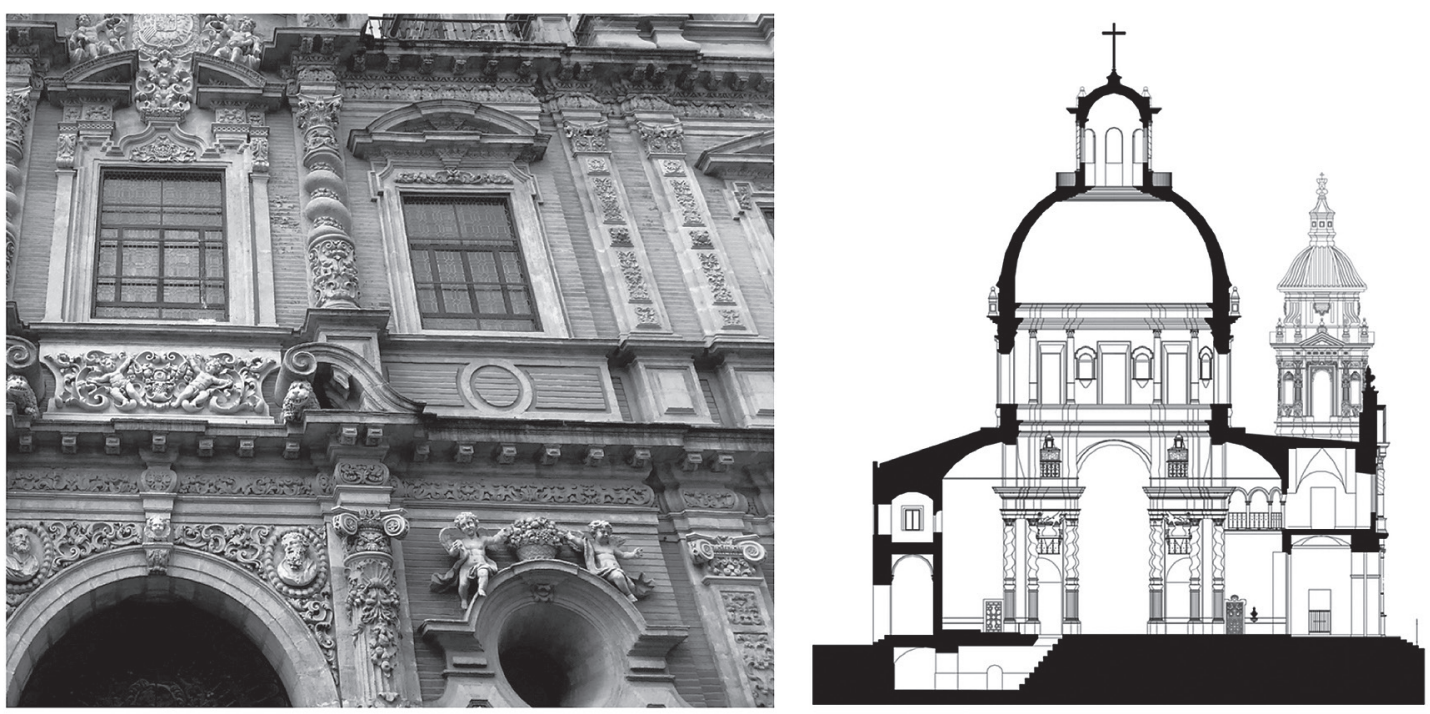

Fig. 1. (Izquierda). San Luis de los Franceses, (fragmento de fachada). Sevilla 1730. Fotografía del Autor. (Derecha). Sección longitudinal de San Luis de los Franceses. Sevilla 1730. Reproducción por el Autor.

HIGUERA MELÉNDEZ, José Manuel. "Leonardo de Figueroa: orígenes, aprendizaje y comienzos del maestro del barroco sevillano", Academia. Boletín de la Real Academia de Bellas Artes de San Fernando. Primer y Segundo semestre 2012-2013. Números 114-115. Sevilla.2013.

$6 \quad$ BÖSEL, Richard. "L'architettura dei nuovi ordini religiosi”. En Scotti Tosini A. (ed.), Storia dell'architettura italiana. Il Seicento, Electa. Milán. 2003. pp. 48-69. 
de la construcción de la Colegiata de San Luis de Villagarcía de Campos y en la decoración interior de la Iglesia, sobre todo en el Retablo y Custodia del Altar Mayor ${ }^{9}$. Esta Iglesia pasó a ser un referente arquitectónico jesuítico en la provincia vallisoletana. El diseño inicial de R. Gil de Hontañón, estuvo asociado a la concepción del "noster modus" y posteriormente fue revisado por Pedro de Tolosa, sirviendo esta segunda orientación como taller de formación de un buen número de coadjutores jesuitas ${ }^{10}$.

Después de Valeriano, ejercieron de consiliarius aedificiorum los matemáticos del Colegio Romano Giovanni de Rossis, (1538-1610), Christoph Grienberger, (1564-1636) y Oracio Grassi, (1583-1643), que además de su reconocida producción científica, participaron de la construcción de importantes edificaciones siendo responsables de la supervisión y autorización de innumerables obras de la Compañía en distintas provincias y países.

Por otra parte, Oracio Grassi había impartido también a los hermanos de la Compañía cursos de perfeccionamiento arquitectónico debido a la necesidad que tenían de personal preparado en esta profesión. Así mismo, Christopher Grienberger ${ }^{11}$ fue profesor de matemáticas, física, y probablemente de nociones básicas de arquitectura, de los misioneros destinados en la India.

Durante un breve periodo de tiempo los profesores fueron sustituidos por un sencillo her-

9 PÉREZ PICÓN Conrado, S.J. Villagarcía de Campos: Estudio histórico-artístico. Institución Cultural Simancas. Diputación de Valladolid. 1982, pp.94-96.

10 BUSTAMANTE GARCÍA, Agustín. La Arquitectura clasicista del foco vallisoletano. (1561-16 40).Valladolid: Institución Cultural Simancas. 1982, pp.53-70. Ver también en MARTÍN GONZÁLEZ, Juan José. "La Colegiata de Villagarcía de Campos y la Arquitectura Herreriana". En Seminario de Estudios de Arte y Arqueología, XXIII, Valladolid, 1957, pp.19-40; PIRRI, Prietro. Giuseppe Valeriano, S.J. Architectto e Pittore, 1542-1596. 1970. Roma, p. 27; RODRIGUEZ G. DE CEBALLOS, Alfonso. Estudios del Barroco Salmantino. El Real Colegio de la Compañía de Jesús (1617-1779). Salamanca: Centro de Estudios Salmantinos, 1969, pp.19-30; RODRIGUEZ G. DE CEBALLOS, Alfonso. La Arquitectura de los Jesuitas. Edilupa Ediciones S.L. Madrid, 2002.

11 BALDINI, Ugo. "L'insegnamento della matematica nel collegio di S.Antao a Lisbona, 1590-1640".En: A Companhia de Jesus e a missionaçao no Oriente, GONÇALVES, N. da Silva (ed.), Fundaçao Oriente, Lisboa, 2000, pp.275-310. mano lego, Andrea Pozzo ${ }^{12}$, (1642-1709), que se estableció como artista polifacético, pintor perspectivista y arquitecto de sólida experiencia. Su estudio fue una especie de academia en la se aprendía perspectiva, pintura y arquitectura, en sintonía con los seminarios de Física y Matemática que los profesores explicaban a pequeños grupos de jóvenes investigadores en el Colegio Romano. Su obra, Perspectiva Pictorum et Architectorum ofreció a los jesuitas de todo el mundo un didáctico manual para la práctica del diseño arquitectónico y constituyó un estímulo para poner de manifiesto una "cultura jesuítica" de la perspectiva. Desde este punto de vista, su espectáculo arquitectónico se mezcla y confunde con la arquitectura real.

En este contexto, puede considerarse que la arquitectura de los jesuitas tuvo tres períodos bien definidos. El primero de ellos se caracterizó por tipologías y estructuras muy sencillas, austeras y muy funcionales. El segundo, entre los siglos XVI y XVII, en el que la Compañía construye su gran red de colegios y el tercero, localizado entre el siglo XVII y XVIII, y que llamaríamos propiamente decorativo, en el que están presentes los atrios con pinturas ilusionistas, los grandes frescos pintados con la técnica perspectivista, las imágenes, y todos aquellos aspectos decorativos que complementaban la grandiosidad de la obra. A este tercer periodo pertenece la Iglesia de San Luis de los Franceses. Esta ubicación temporal explica las posibles influencias del consiliarius A. Pozzo, en el diseño y ornamentación de San Luis de los Franceses de Sevilla.

\section{Estilo Jesuítico y Noster Modus}

Pero el análisis de la arquitectura de la Compañía de Jesús ha sido y es una fuente inagotable para investigadores, generándose un debate entre los dos términos utilizados para concebirla: "estilo jesuitico" y "noster modus". El primero de ellos fue acuñado a mediados del XIX, interpretando la excesiva decoración detectada en los edificios de la Compañía para buscar la atención de los fieles. Incluso pudo haberse

BÖSEL, Richard. "La perizia pratica - Andrea Pozzo, consiliarius aedificiorum della Compagnia di Gesu”, en Mirabili disinganni. Andrea Pozzo (1642-1709), pittore e architetto gesuita, BÖSEL, Richard, y SALVIUCCI, Insolera, Lydia, (ed.), Artemide, Roma, 2010, pp.217-221. 
creado un cierto estado de confusión entre el llamado "estilo jesuítico" y el "estilo barroco", si en el análisis se atiende fundamentalmente a la decoración barroca de algunos templos de la Compañía de Jesús. Según Czeslaw Milosz, Premio Nobel de Literatura en 1980:

"A Europa la define sobre todo la arquitectura y dentro de ésta el Barroco, esa explosión que extendieron los jesuitas"13

Por otra parte, existen investigadores ${ }^{14}$ que explican el "estilo jesuitico" como un estilo romano clásico, poderosamente influenciado por Vignola. Richard Bösel, investigador del Instituto Storico Austriaco de Roma y uno de los especialistas más reconocidos en el arte de la Compañía de Jesús, nos muestra su punto de partida para cualquier análisis de la llamada "arquitectura jesuitica". Bösel defiende lo inadecuado del término "estilo jesuítico" y plantea la interpretación que se debe dar a dicho término ${ }^{15}$. Por ello, su "ratio aedificiorum" debe interpretarse como un "modo de proceder" reglado al estilo de los jesuitas y por lo tanto, controlado desde Roma que visaba y aceptaba la idoneidad de los distintos proyectos procedentes de los hermanos arquitectos y constructores. En este sentido, siendo Leonardo de Figueroa conocedor de la obra de A. Pozzo, es muy posible que éste conociera el proyecto de Figueroa para San Luis de los Franceses, aspecto sobre el que Rodríguez Ceballos escribe:

\section{[...] y quién sabe si el propio Pozzo lle-} gó a dictaminar el proyecto de Leonardo Figueroa para la iglesia de San Luis, que tuvo que enviarse necesariamente a Roma para su aprobación antes de 1699. La verdad es que las curiosas columnas salomónicas de piedra caliza que rodean la parte inferior del cilindro de San Luis, flanqueando las aberturas de la capilla mayor y de los brazos subsiguientes del crucero y del pórtico de entrada, parecen estar tomadas, tanto en su forma como en su

13 Declaración sobre Europa del Nóbel Czeslaw Milosz recogida el 15/8/2004 en el Diario ABC.

14 WITTOKOWER, Rudolf. y JAFFE, Irma. B., (ed.), Baroque Art: The Jesuit Contribution. Fordham University Press. New York., 1972.

15 BÖSEL, Richard. "La ratio aedificiorum di un'instituzione globale: tra autoritá centrale e infinità del territorio". Simposio Internacional "La arquitectura jesuitica”. Zaragoza, 2010, pp.39-41. disposición, del dicho tratado, como intentaré demostrar. ${ }^{16}$

La aceptación del término "estilo jesuítico", a pesar de los esfuerzos de historiadores, artistas y arquitectos por eliminarlo, siempre estuvo latente como tema de debate. Consecuentemente la fuerza de un mal llamado "estilo jesuitico" se basó fundamentalmente en la interpretación del arte en función de la influencia que tuvo la propia mentalidad jesuítica, sobre todo, en los países católicos y tierras evangelizadas del nuevo mundo. Si bien es cierto, como se ha dicho anteriormente, que en un principio todo lo puramente arquitectónico pasaba por la decisión del consultor interno, no es menos cierto que Compañía nunca tuvo interés en imponer un "estilo" característico a sus empresas arquitectónicas y artísticas. Sobre esta libertad estilística puesta de manifiesto en el Simposio celebrado en 1992 en la Universidad de Fordham (EE.UU.) bajo el título "Baroque Art: The Jesuit Contribuction", los historiadores Rudolf Wittkower y James S. Ackerman centran con toda claridad el tema objeto de estudio, admitiendo que existió dicha libertad estilística y estética así como una versatilidad y adaptabilidad a las preferencias y tradiciones locales. Entre sus conclusiones se insiste en la facilidad de Compañía y otras órdenes religiosas para trabajar con numerosos artistas que dejaron un magnífico legado de su potencial artístico, aunque es poco probable demostrar su influencia en la creación de un estilo propio. Es conocida la relación que tuvo la Compañía de Jesús con grandes artistas como Ammannati, Rubens, Pietro da Cortona, Borromini y Bernini, cada uno de los cuales cultivó un estilo personal y característico. Aun así, los arquitectos consultores, como Tristano y Valeriano, fueron los mejores exponentes arquitectónicos de los primeros momentos de la “arquitectura de los jesuitas". Una acción posterior podría estar ejercida por la actividad de los matemáticos, De Rossis, Grienberger y Grassi, que participaron activamente en la dirección de proyectos arquitectónicos en distintos países. Concretamente, los conceptos de nave única,

\footnotetext{
16 RODRIGUEZ G. DE CEBALLOS, Alfonso. "Reconsideración de la Iglesia del Noviciado de San Luis de Sevilla, a la luz del Tratado del Jesuita Andrea Pozzo". En La Compañia de Jesús y las Artes: nuevas perspectivas de investigación/ coord. María Isabel Álvaro Zamora, José Ibáñez Fernández. 2014, pp.323-324.
} 


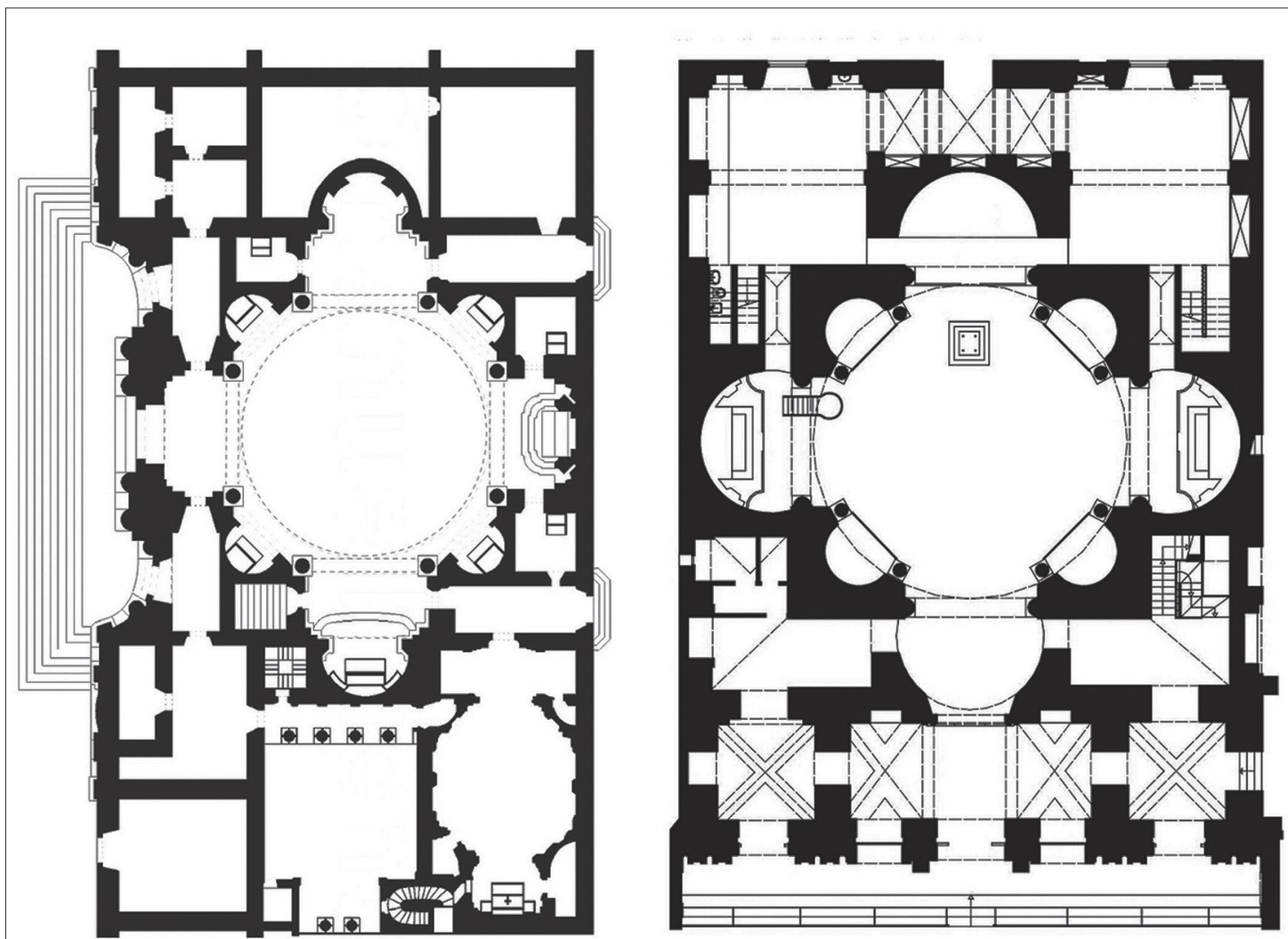

Fig. 2. (Derecha). Planta central de San Luis de los Franceses. Sevilla 1730. Dominio público. (Izquierda). Planta de la Iglesia romana Santa Inés de Navona 1672. Reproducción del Autor.

capillas, estudios sobre ábsides atribuidos a De Rossis están asociados a un discurso arquitectónico propio de la "arquitectura de los jesuitas"17. Consecuentemente, la "joya sevillana” San Luis de los Franceses ${ }^{18}$ es fruto de esa libertad artística y estilística conceptualizada por los citados historiadores. Su originalidad gira

1 SCHWAGER, Klaus. "La Chiesa del Gesú di Roma". En: Jacopo Barozzi da Vignola, TUTTLE, R. J., ADORNI, B., LUITPOLD, Ch., THOEES, Ch., (editores). Electa. Milán. 2002. pp.272-299.

18 CAMACHO MARTINEZ, Rosario, "La Iglesia de San Luis de los Franceses en Sevilla, imagen polivalente. Cuadernos de Arte e Iconografía, II, 3, Madrid, Fundación Universitaria Española, 1989, pp. 202-213. Ver también MORALES MATINEZ Alfredo J. "La arquitectura jesuítica en Andalucía. Estado de la cuestión”, en La arquitectura jesuitica, 2012. pp.331-354; LLEÓ CAÑAL Vicente, "Barroco y retórica: el edificio elocuente". En: Andalucía Barroca. Teatro de Grandeza, Junta de Andalucía. Sevilla. 2008, pp. 24-41 y RAVÉ PRIETO Juan Luis. San Luis de los Franceses, Diputación Provincial. Sevilla. 2010. RODRIGUEZ-GUTIERREZ DE CEBALLOS, Alfonso. "Arquitectura y arquitectos en la provincia Jesuítica de Andalucía", en El arte de la Compañía de Jesús en Andalucía, (1554-2004). Caja Sur. Córdoba.2002. pp. 105-111. en torno al trazado de la planta centrada con forma de cruz griega inscrita en un rectángulo, cuyos brazos terminan en forma de espacios vacíos elevándose en el centro del crucero una poderosa cúpula fig. 2 .

Este tipo de planta tiene una gran influencia vitrubiana, encajando con perfección en las figuras geométricas del círculo y el cuadrado que Leonardo interpretó con excepcional maestría. $\mathrm{Su}$ preocupación por la iglesia de planta centralizada le llevó a realizar numerosos dibujos de iglesias centralizadas que muestran los posibles desarrollos del cuadrado y el círculo.

En consecuencia, Figueroa estableció una geometría basada en la combinación del plano centralizado, (gran escala de la cúpula) y el plano basilical (nave única, reemplazando las naves laterales por capillas y otras dependencias). Estos espacios están localizados en las zonas que los brazos de la cruz dejan entre sí, extendiéndose las situadas más próximas a la fachada para formar el pórtico y las torres laterales y las posteriores para dar lugar a la sacristía y almacenes, por lo que en su conjunto se presenta como un rectángulo. Su relación con 
las ideas conceptuales de los artistas del Colegio Romano ( consiliarius aedificiorum), como planimetría, distribución del espacio central en cruz griega, columnas salomónicas con clara influencia de Pozzo, etc., hacen que el proyecto se encuadre dentro la arquitectura del "noster modus". Destacan los vigorosos volúmenes de su fachada y la majestuosa cúpula sobre tambor circular que la corona y provoca una intensa iluminación al conjunto. La vasta labor investigadora desarrollada sobre esta iglesia, a pesar de la escasa información existente en los archivos de la Compañía en Sevilla y Roma, nos permite un conocimiento riguroso de sus aspectos constructivos y decorativos.

Abundando en esta línea, podríamos decir por tanto, que San Luis de los Franceses no es fruto de una tipología propiamente jesuítica, sino más bien la consecuencia de una tipología arquitectónica que se había venido gestando desde 1530 en el norte de Italia, especialmente en Milán. Un indicio de estas influencias italianas está perfectamente definido en su planta que según A. Sancho Corbacho, está basada en la de la Iglesia romana Santa Inés de Navona ${ }^{19}$, fig. 2. Debemos hacer constar que a pesar de su parecido existen algunas diferencias importantes. Por ejemplo, la entrada en Sta. Inés se realiza directamente a través de uno de sus ló- bulos y en San Luis existe un desarrollo previo de la Logia.

Respecto de su decoración predomina la tradición barroca sevillana. Su fachada está compuesta por dos cuerpos en los que aparecen materiales como piedra, ladrillo y vidriados. En su interior destacan las pinturas de Lucas Valdés en la cúpula, el barroquismo exuberante del Retablo Mayor de Pedro Duque Cornejo y el óleo de San Luis de los Franceses pintado por Zurbarán. En este sentido, San Luis de los Franceses es la culminación de unas tipologías ya desarrolladas y el "estilo jesuitico", más que un estilo creado por los jesuitas, responde a un conjunto de formas ya establecidas adaptadas a las necesidades de la Compañía.

Con esta teorización, no sólo se había establecido un modelo de "arquitectura de los jesuitas" para la iglesia barroca utilizando un ordenamiento geométrico, sino que además habría explicado la concepción de lo que llamaríamos "perspectiva jesuita" fundamentada principalmente en la obra de A. Pozzo. La influencia de éste en la composición y ornamentación de San Luis pudo ser importante, sobre todo en lo referente a la admirable ejecución de sus arquitecturas ilusionistas y simbolismos salomónicos en interior y exteriores, fig.3. Así, las calizas columnas salomónicas de San Luis son un fiel

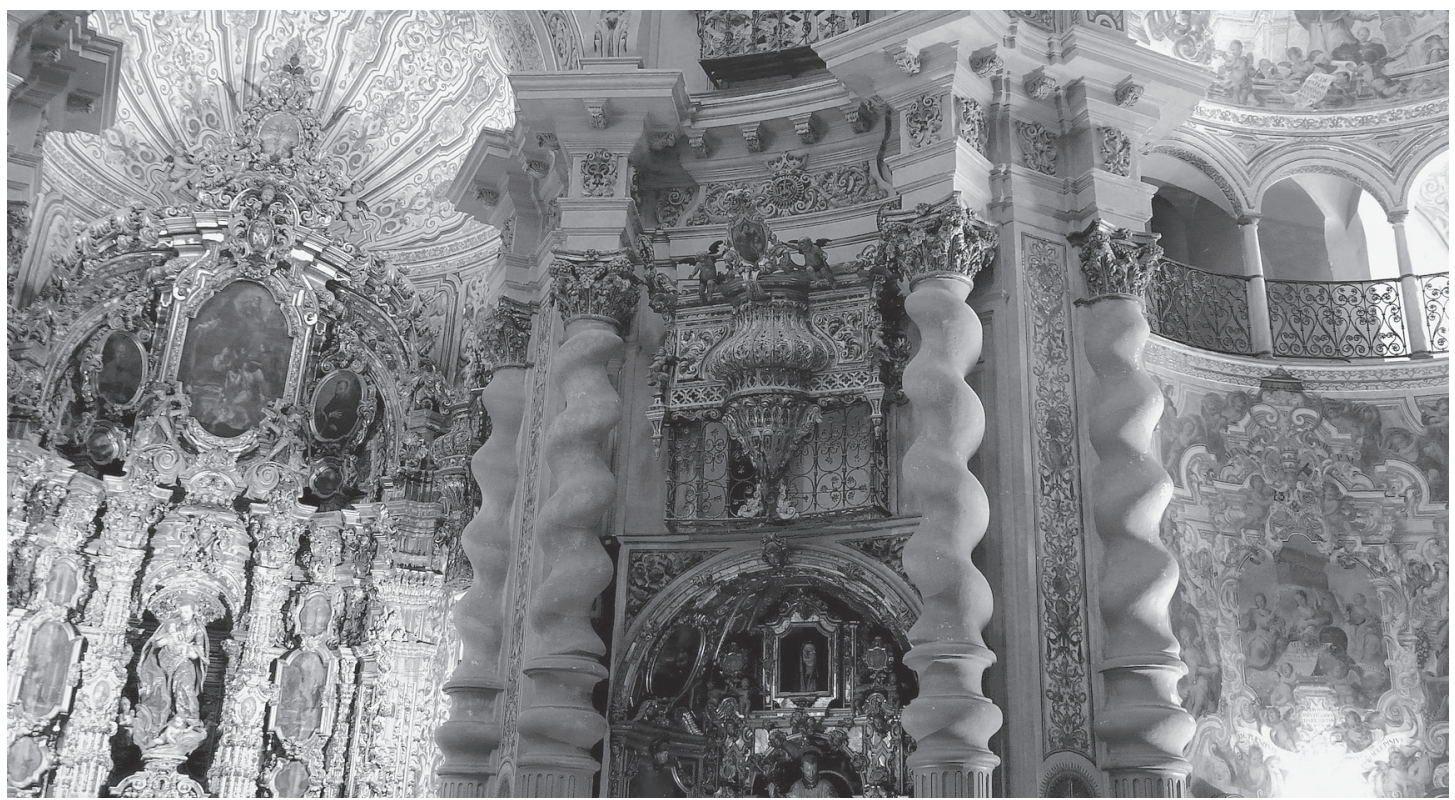

Fig. 3. Altar Mayor y laterales de la Iglesia del Noviciado de San Luis. Sevilla 1730. Fotografía del Autor.

19 SANCHO CORBACHO Antonio. Arquitectura sevillana del siglo XVIII, Instituto Diego Velázquez, CSIC. Madrid. 1952, pp. 85-94. 


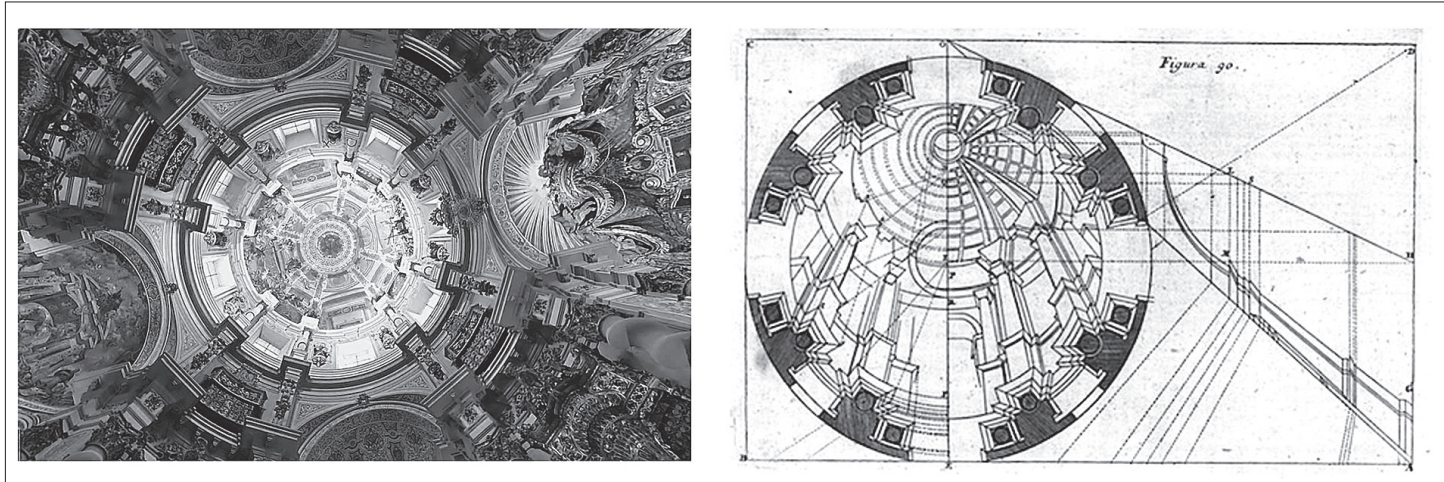

Fig. 4. Cúpula de San Luis de los Franceses. Sevilla 1730 (fotografía del autor), frente a la geometría para la arquitectura fingida de una cúpula de A.Pozzo, Perspectiva Pictorum et Architectorum (2 volúmenes, 1693-1698) (Dominio Público).

reflejo de las que Pozzo llamó espirales en su obra Perspectiva, Pictorum et Architectorum ${ }^{20}$.

Algunos componentes destacables en la fachada y arquitecturas imaginadas de la decoración interior, óculos, campanarios al estilo de los tabernáculos de Pozzo, frescos y otros elementos menores, a veces, desde su más pura esencia quadraturista y en ocasiones disfrazados con localismos pictóricos y arquitectónicos, tienen una clara influencia del artista jesuita.

Es evidente, que si aceptamos que los jesuitas no desarrollaron un "estilo" tampoco es apropiado hablar de "arquitectura jesuitica". En nuestra opinión, lo que sí ha podido existir es una tipología española, (acertadamente sevillana en el caso de San Luis), portuguesa o italiana, basada fundamentalmente en "il Gesú" de Roma, que más que un modelo, constituyó una "herramienta" tipológica.

Esta consideración, con la ayuda de la escasa bibliografía, revistas y libros especializados en arquitectura de la época, nos permite afırmar que los arquitectos jesuitas recopilaban documentación de las distintas obras que Roma visaba y que con ligeros retoques fueron modificados y adaptados a las características de la acción misional concreta y de los lugares en los que se construían. En consecuencia, más que hablar de un "estilo jesuitico" a través de su influencia espiritual, Wittkower afirma que en todo caso sucedió más bien al contrario: "fueron los grandes artistas los que influyeron en la obra jesuítica". Esta sentencia corrobora que San Luis de los Franceses, entre otras obras de la Orden, fue fruto de las teorías arquitectónicas del Humanismo que buscaron ansiosamente la perfección a par-

20 P0ZZ0, Andrea. Prospectiva de'pittori ed architetti. Primera parte. Roma 1741. tir de un juego mágico de volúmenes y formas, fig.4. Su composición arquitectónica dependió estrictamente de la geometría, la racionalidad y la lógica y en los espacios interiores, existió una obsesión permanente por la iluminación de las formas ${ }^{21}$. Por otro lado, si nos centramos en el término "noster modus", podemos entenderlo como el "conjunto de exigencias que planteaban las distintas fundaciones de la Compañía en función de aquello que tenían que administrar y en la forma que deberían hacerlo". Por lo tanto, su interpretación está relacionada con lo funcional o constructivo, nunca con el punto de vista estilístico. Sin embargo, otros investigadores ${ }^{22}$ opinan que el "noster modus" era "un esquema tipológico y organizativo" que obedecía a motivos de tipo práctico, necesidades para la formación y docencia, acción misional y funcionalidad, características que otorgaban a la arquitectura de los jesuitas un aspecto ciertamente particular y fácilmente reconocible a través de ese "modo de proceder". Era, a juicio de otros investigadores ${ }^{23}$, un "modus procedendi" que de alguna manera tenía en cuenta el régimen normativo de la Compañía. El mismo Gauvin Bailey plantea una sintesis muy acertada para diferenciar ambos términos cuando dice: "noster modus" is not a product but a process" 24 . La reciente historiogra-

${ }^{21}$ CABEZA LAÍNEZ, JOSÉ MARÍA Y ALMODOVAR MELENDO José Manuel. "Rehabilitación y Simulación ambiental del Patrimonio. Noticia del barroco. El caso de la Iglesia sevillana de San Luis de los Franceses." Revista de Historia y Teoría de La Arquitectura. №. Sevilla.1998.

22 COSCORELLA, C. "La tipologia della chiesa gesuitica". En: "L'architettura della Compagnia di Gesù in Italia. XVI-XVIII". Grafo. Brescia.1991. pp.11-14.

23 BÖSEL, "La ratio aedificiorum ....."opus cit. pp.39-41.

24 BAYLEY, Gauvín Alexander. "Le Jesuits: cultures, sciences and the arts, 1540-1773". Editor John W. 
fía de la Compañía de Jesús, cuando se refiere a la aplicación de los principios ignacianos (Ejercicios Espirituales) y otros documentos del Instituto de la Compañía, como decretos congregacionales, reglamentos, y ordenanzas, se concreta la forma en la que habían vivido y trabajado e incluye, todos los documentos oficiales de la Orden. La misma palabra "Instituto" es sinónimo de lo que se ha convenido en llamar "noster modus" o "nuestro modo de proceder", sin que ello tenga una relación directa con el comportamiento arquitectónico de los artistas jesuitas. En este modelo se enmarca la iglesia de San Luis de los Franceses que fundamentada en las teorías del humanismo arquitectónico, las adapta a las exigencias del "noster modus" como Iglesia del Noviciado de la Compañía de Jesús en Sevilla (España). Sin embargo, su vertiente formativa relacionada con los estudiantes del Noviciado no ha sido suficientemente investigada. En la casa de Dios, éste no es tangible, no tiene imagen y por lo tanto su representación debía hacerse mediante símbolos. Esta es una característica esencial de San Luis de los Franceses en la que los relicarios en Altar Mayor y muros laterales de la Iglesia, pinturas de Apóstoles, escenas de la vida de la Virgen María, pinturas en bóvedas y arquitectura fingida de la cúpula con imágenes y símbolos de Lucas Valdés, alegorías a los símbolos jesuíticos etc. ${ }^{25}$, hacen de ella un poderoso instrumento de "muta predicatio" 26 de alto valor contemplativo y objeto de meditación.

0’Malley, University of Toronto Press. Toronto, London. 2000. p.73.

25 Ver en CAMACHO MARTINEZ, Rosario, “ La Iglesia de San Luis de los Franceses...." opus cit., pp. 211-213.

26 Este término lo utiliza CORSI Elisabetta para explicar la importancia de la imagen como objeto de meditación en su artículo Constructores de fe. Imágenes y arquitectura sagrada de los jesuitas en el Pekin imperial tardio. Historia y Grafía, n²6. Distrito Federal, México. 2006, pp. 150-152.

\section{Conclusiones}

29

Frente a los defensores de un "estilo jesuitico" o "noster modus" en la arquitectura sacra de los siglos XVI-XVIII, este trabajo profundiza en la diferenciación entre ambos términos, y su relación con las teorías arquitectónicas humanistas como aglutinante de la llamada "arquitectura de los jesuitas".

La rigurosa reflexión desarrollada sobre dichos términos, "estilo jesuitico" y "noster modus", nos ha llevado a descubrir una nueva forma de ver la arquitectura de los jesuitas. A partir de las contribuciones de Rudolf Wittkower, y James S. Ackerman, podemos constatar que las aportaciones de los artistas y arquitectos de tradición humanista, influyeron poderosamente en las construcciones jesuiticas sin llegar a constituir un estilo jesuitico, como es el caso de San Luis de los Franceses. Consideramos además, que el término "noster modus" no está relacionado con las tipologías arquitectónicas aunque tiene un gran contenido ideológico desde su propia simbiosis con el llamado Instituto de la Compañía de Jesús. Consecuentemente, en muchas de las grandes obras de la arquitectura sacra jesuítica, como es el caso de San Luis, primaron las exigencias del "noster modus" sobre cualquier referencia estilística. 